\title{
ACHIEVING EXCELLENCE IN PATIENT SATISFACTION THROUGH BETTER HOSPITALITY AT HOSPITALS: STUDY OF DELHI-NCR
}

\author{
RAJNISH SHUKLA, DR. MALINI SINGH \& DR. SANJIV KR. SAXENA
}

Research Scholar, Amity University, Uttar Pradesh, Noida, India

Associate Professor, Amity University, Uttar Pradesh, Noida, India

Gm - Hrd, Jaypee Palace Hotel \& Convention Centre, Agra

\begin{abstract}
This study is conducted to explore the possibility of achieving the excellence in patient satisfaction through better hospitality in multispecialty hospitals of Delhi NCR. The study aims at exploring the philosophy and practices in hospitals, which are hospitality centric and contributing to the overall patient satisfactions. An exploratory case study research method is used as it was matching the research purpose. Hospitality domains and its applications were identified from literature review and organization wide philosophy of hospitality centric patient care and its programs were defined and described. Researcher believes that an efficiently managed Patient Centric Hospitality Policy (PCHP)can be further enhanced to Patient Centric Hospitality Philosophy (PCHP) and can be utilized to achieve the excellence in patient satisfaction through better service experience.
\end{abstract}

KEYWORDS: Hospitality, Patient Satisfaction \& PCHP

Received: Jun 08, 2020; Accepted: Jun 28, 2020; Published: Sep 15, 2020; Paper Id.: IJMPERDJUN20201246

\section{INTRODUCTION}

In existing literature, recently many studies are focusing on the care provided to patients and wellbeing of the patient has significantly emerged in focus for the hospitals (Andrade \& Devlin, 2015). Most of the earlier researches suggest that a hospital environment does carry an impact on patient satisfaction (Evans \& Mccoy, 1998). Many recent researches suggest that hospitals need to be more hospitable, i.e: having patient centric environment. This idea that the physical facility and service offered can play an important role on the patient wellbeing, is an old understanding (Healing Places - 9780742519565, n.d.)(Gesler 2003). Meaning of patient's centered care which explains the concept of "more hospitable hospitals" covers not only the hotel like design of healthcare facility and also the operational excellence and staff interactions with patients (Silvis, 2013).(Andrade \& Devlin, 2015)

In previous studies done on the applying the concept of service to patient's experience in hospital, importance of cleanliness of environment and friendliness of employees, in promoting the patient recovery, was found(Hussain et al., 2019)Level of kindness and consideration in patient encounters with staff and the way patients perceived their environment, was found to have a significant effect on their overall satisfaction(Gesler et al., 2004) In present times studies have suggested that better service will ensure that patient is not there in hospital for long(Cohen, 2004).Hospitality style empathetic service, if offered to patients, will bring the reduced stress levels among patients and inturn enhance the healing process by increasing the patient comfort. Thus, how a building looks and how the services inside the building feel, can bring better patient satisfaction (Wu et al., 2013). Wellmannered and empathetic service from staff uplifts the spirits and also supports the faster recovery and thus inspires 
staff to give better services (Kitapci et al., 2014). In 2016, during "Hospitality health and design symposium" at Cornell University, all delegates presented the appreciation for "importance of patient environment to recovery and wellness". It was brought forward that hospital buildings should integrate hotel like design and infrastructure that will enable the hospital employees to render the empathetic \& patient-centred service and care (Verma et al., 2016)(CIHF Hospitality, Health, and Design Symposium Featured in Article - Cornell Institute for Healthy Futures, n.d.)

Healing environment of the hospitals consists of physical environment \& social dimensions and both together as service scape frame work has significant impact on the patient health. (Bitner, 1990, 1992).In 1995, Hutton and Richardson (Hutton \& Richardson, 1995)has designed a model of this service-scapes and called it healths capes model. One can easily find enough evidence in scholarly literature to say that health organizations shall align their focus from being purely medically focused and clinically oriented to a balance of actions and behaviours which are medically right and clinically required but also brings a more hospitable environment through supportive hospitality-oriented design and services. (Evans \& Mccoy, 1998; Rathert et al., 2013; Sloane, 2001)

Available literature has presented many insightful indications of healthcare scapes including both physical and social environment which supports the well-being of patients, but it's impact on patient satisfaction remains under researched and not enough attention is given for incorporating the hospitality elements in present modern healthcare setups. (Suess \& Mody, 2018; Wu et al., 2013)

Though the facts are well established but research towards the impact what patient centric hospitality philosophy can bring on patient satisfaction has not been there and that brings a perfect motivator for this research.

\section{RESEARCH OBJECTIVES}

In the given background this research is aimed the following objectives -

- Researchers will attempt to describe and discover Hospitality and its philosophy in healthcare setup to define PCHP - Patient Centric Hospitality Philosophy.

- To discover the support functions and Patient Centric Hospitality Programmes (PCHPr.)

- Finally recognize and classify the Patient Centric Hospitality Programmes (PCHPr.), helping in establishing PCHP, as practiced in Hospitality Industry.

\section{LITERATURE REVIEW}

In 2000 Lashley and Morrison explained hospitality as a promiseand assurance to meet guest's needs as a prime objective in any commercially run service industry setup. This was further explained as a reciprocal relationship between a guest and a host (Lynch et al., 2011; O’Gorman, 2007)

Hospitableness comprises of a friendliness and warmth in receiving and delivering, attitude and environment (Oh et al., 2008)These two, supported by genuine company philosophy go beyond creating an excellent service environment. excellent service to create rememberable experiences(Kelly et al., 2016)Analysed from this angle an organizational policy and meaning of hospitality is applicable to, and can help improve all human exchanges in any enterprise. A healthcare setup where the customer is a sick guest, will provide a perfect example for testing the level of contentment in guest - host exchange. As per Pizam - "the difference between hospitals and hospitality is 'ity', but that 'ity' can make a significant 
difference in the recovery and stay of hospital patients(Pizam, 2007).Lashley observed that some hospitals have adopted integrated patient care programmes that have definitely improved the customer experience by bringing strategies and working patterns used that of in hospitality industry(Lashley, 2015) These work patterns and strategies have aimed at improving the process and people interactions at every level towards giving better patient experience (i.e. enhancing the practical quality aspects of service). This includes enhancing the genuineness of efforts, warmth of reception and psychological \& emotional well-being of customers involved as patients and their attendants(Panchapakesan et al., 2015)

In 1999 Brotherton defined hospitality as an exchange or interaction between provider and receiver, involving some tangible and non-tangible factors, providing the sense of security with psychosocial \& physiological comfort of the guest (Brotherton, 1999). In contrast to an ordinary hospitality setup where the guest is voluntarily there for leisure or business, In Health care setup, due to fear, illness \& inhabitancy, caused by non-voluntarily nature of their stay, role of cognitions and emotions is super imposed on other comforts. Thus, bringing the greater need for emotional attention and psychological comfort, and they are also associated with increased need for physical proximity (Domenico and Lynch, 2007; Hemmington, 2007). In a healthcare setup the importance of hospitality is multiplied due to increased emotional need and personal proximity and interactions and thus bringing more service interactions or exchange opportunities (Lynch, 2005).

Some parallels between other hospitality driven organizations and healthcare setups are - comfortable stay, 24/7 in room service, security, choices in food and dinning, entertainment, library, laundry, internet services, maintenance etc. Similarly, in both business environments, organizers need to be able to integrate and deal with different type of guests parallelly towards their unplanned variances in demands. Both industries recognise the indirect guests in form of visitors of their guest, and must understand their importance for the enterprise. In both types of organizations, all types of guests, inhouse or visitors, will be evaluating the service encounters to form their perceived experience which will affect their future intentions and buying behaviours. (Suess \& Mody, 2018)

In Past many researches have shown that implementing the hotel like amnesties and hospitality environment can deliver a positive patient experience(Haque et al., 2012) But there has not been any study to explore the hospitality philosophy practiced to go beyond the normal services offered. Some case studies have attempted to study the organization wide hospitality philosophy in hospitals and gave some insight on it (Severt et al., 2008a). In 2007, Reynolds and Leeman stated that hospitality services like, registrations, food, cleaning, \& concierge, can bring better patient satisfaction when managed more efficiently. Most of the healthcare studies have not touched upon the subject of overall service strategy, perceived quality and Philosophy of patient centric services (Reynolds \& Leeman, 2007)

Swapanragswain, in 2018 explained the importance of the hospitality centric healthcare services, for caregivers. The author suggested three different types of hospitality is embraced by all the caregivers. All the customer interactions were classified in three categories as "Public Hospitality, Personal Hospitality \& Therapeutic Hospitality" (Swain \& Kar, 2018). Public hospitality is defined as a courteous smile and courteously done basic service which is illustrated in the courtesy demonstrated in Hospitality Organizations. Personal Hospitality is little more than public courtesy and touches the personal domain of the guest interactions. For Example, interactions like, assurance, empathy, self-disclosure, and sharing interests will come in this category. Ina healthcare setup it is more commonly seen in nursing care and emergency rooms where the interactions are more intimate and emotionally intense. Lastly the Therapeutic Hospitality comprehends the service to human being which is more religious, ethical, holistic, and spiritual in nature. This connects people to people as 
pure human beings and reduce the loneliness and sense of separation. This hospitality has an emotional healing touch. (Severt et al., 2008b)(Kelly et al., 2016)(Hospitality in Hospitals: The Importance of Caring about the Patient, n.d.)

Patient-centred care is - "the practice of caring for patients (and their families) in ways that are meaningful and valuable to the individual patient. It includes listening to, informing and involving patients in their care". As per IOM (Institute of Medicine) patient-centred care is "Providing care that is respectful of, and responsive to, individual patient preferences, needs and values, and ensuring that patient values guide all clinical decisions". (Picker Institute's Eight Principles of Patient-Centered Care | National Center for Interprofessional Practice and Education, n.d.)

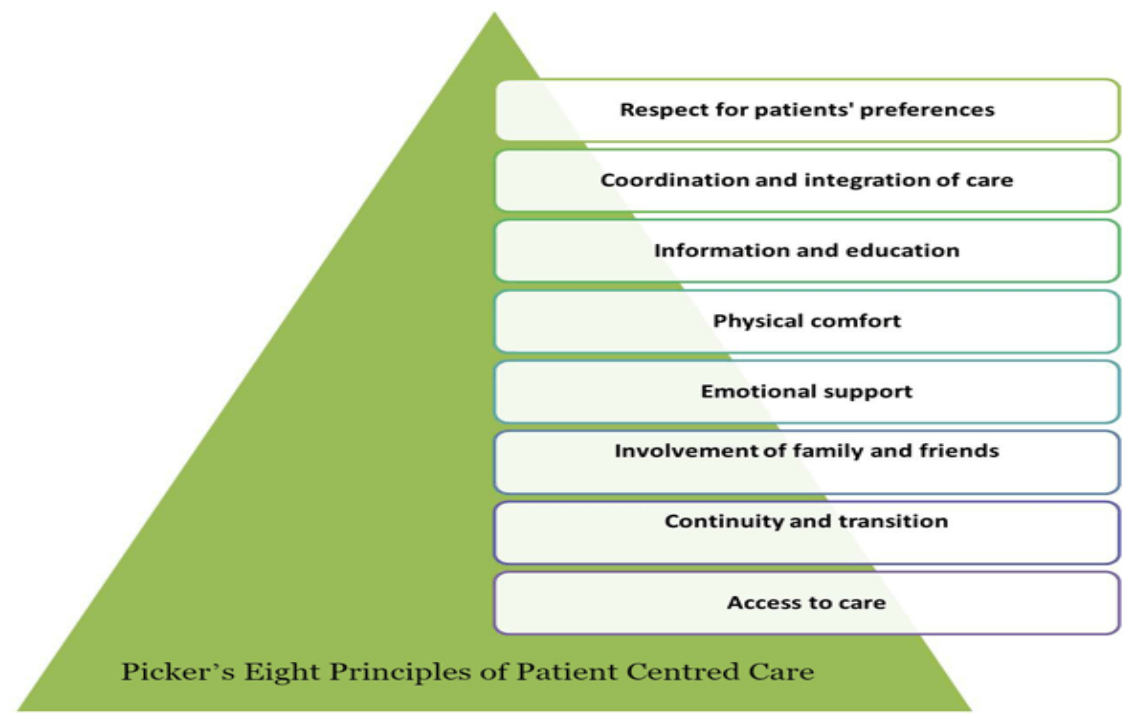

(Oneview, 2015)(Davis et al., 2005; "Picker Institute's Eight Principles of Patient-Centered Care | National Center for Interprofessional Practice and Education", n.d.)

\section{METHODOLOGY}

For this exploratory research, case study method is found to be appropriate and used. (Creswell 2003 - Google Search, n.d.)An exploratory study method is adopted to find out the hospitality elements (HE), as applied to the healthcare industry. All the hospitality elements were identified and defined from expert interview and the literature review. For construct validity researchers have used structured observations through expert interviews, semi informal discussions and unstructured observations, while moving around in hospital premises. During the data collection and observations, the researchers has maintained inductive and open-ended approach but while analysing the information thus collected, theoretical and deductive approach was used (Handbook of Hospitality Marketing Management - Google Books, n.d.).

First, the researchers made a list of hospitals needed to visit and then the meetings and semi structured discussions were arranged. 7 JCI accredited multi-speciality hospitals were chosen for the study. Multiple visits to each of the hospitals, for observations and informal interview were conducted and detailed notes for all the observation and interviewswas noted down, and all these interviews were conducted with transcribed verbatim.

In an attempt to have better construct validity, all the collected information was compared, all the discrepancies and non-consistencies were recorded for clarification asked for in subsequent visits.All the Unfamiliar terms were verified with experts from hospital. 
Key contact point of contact, in most of the hospitals were Hospitality services Manager, patient services manager, hospitality manager OR guest relation manager. Hospital HR department was approached to gain the permission to meet the other staff and conduct the study.

\section{Data Collection}

The data for this research was collected in 9 months between April 2019 to Jan 2020, by researchersthemselves and by making the regular visits to different hospitals and meeting the concern authorities in premises. Once the access was granted by hospital authority, regular visits as observer and spending few hours in every visit was planned. Structured observation through structured interview on a pre decided set of questions were conducted to explore all the elements of hospitality offered in these hospitals. During the multiple visits to the hospitals, unstructured but focused observations were also made to note the visible elements applied for the service environment. Apart from these some documents like training plans, vision and mission of patient service departments, quality policy in place, organogram and reporting structure of support services, etc were also collected and parallelly compared with the primary data collected through observations and discussions. Based on evidences from all sources, Patient Centric Hospitality Philosophy, was studied. Assimilation of all the data collected gave the confidence for the study that methods used is providing a truthful and precise view of Hospitality Philosophy and hospitality policy in place, in these hospitals.

Though detailed review of the literature and subsequent visits to the selected hospitals and interactions with patient care managers, different domains of hospitality, as applicable to healthcare setup were identified. All the tangible and intangible hospitality services and programmes, as explored, were classified into different type of Patient Centric Hospitality Programmes - PCHPr. Each hospitality programmes provides a policy frame work for performing the hospitality services in that domain with a measurable performance outcome and still not mutually exclusive action but is a part of larger Hospitality Policy.

Hospitality Policy wasviewed as framework prepared for a broadly specific yet precise view of patient's expectations and committed deliverables, making it easy to convert those into executable policies describing actions and procedures which are measurable for their outcome.

\section{Research Findings}

All findings of the research are categorized in to describing the Patient Centric Hospitality Philosophy - PCHP and supporting Patient Centric Hospitality Programmes - PCHPr., and also describing the different domains of hospitality covered by these programmes. Aligning with goal of Hospitality Philosophy, the Hospitality Programmes are executed to enhance overall service excellence.

\section{Patient Centric Hospitality Philosophy - PCHP}

Collective knowledge and understanding gathered from these hospitals about their philosophy towards the hospitality for patients, researchers found that having slight difference among all, yet a common and strong indicative Patient Centric Hospitality Policy supporting the Hospitality Philosophy was in place in selected hospitals.

“A customer is the most important visitor on our premises. He is not dependent on us. We are dependent on him. He is not an interruption in our work. He is purpose of it. He is not an outsider in our business. He is part of it. We are not doing him a favour by serving him. He is doing us a favour by giving us an opportunity to do so" -Mohandas Karamchand 


\section{Gandhi, Mahatma Gandhi.}

Hospitals has a vision and mission for enhancing the overall health and ultimate quality of life of the patients and their families served. As a policy or the philosophy of hospitality, which is patient centric, the research provided the following key view about "Hospitality in Hospitals":

"Many times, a patient has only one or two hospital admission as experience during their lifetime. Based on the hospital encounters and owning to the high psychological and emotionalvalue associated with it, these visits are converted to strong memories. Some to cherish and some to not. These experiences areoften shared with others either as a positive encounter or a bad dream. By incorporating a sensible and responsible hospitality element in patient encounters, the future patients can be brought in to the facility, with ease of visit and without any fear".

As one deceleration all Hospitals believe that patient's health andexperiencescan be improved with better hospitable encounters.

Hospitals believe that stronger hospitality philosophy does not mean to make the excellence in medical care as secondary but this shall work as two wheels of the cart working tightly together to create the better customer perception of service quality, which finally becomes the service standard and benchmark. Since most of the patients can hardly evaluate the quality of the medical services received, most often they are perceiving the service quality and assessing the medical care also through hospitality services. If we aim for excellence in hospitality services. We can easily achieve overall serviceexcellence and better customer satisfaction.

"Patients and attendants treat the interpersonal aspect of care as the most important one, as they cannot fully evaluate the technical quality of healthcare services". She also found that holistic approach for Indian healthcare services have brought an understanding that, - Attendants are also important customers as they are like a proxy customer, evaluating all the services and facilities on offer (Padma et al., 2014)

\section{Patient Centric Hospitality Programmes - PCHPr}

The following Patient Centric Hospitality Programmes-PHCPr. were identified and described as major contributors towards the PCHP - patient centric hospitality philosophy. -

- Infrastructure Design Concepts

- $\quad$ Service Orientation of Personnel

- $\quad$ Supplies and Amenities

- Administrative Procedures

- $\quad$ Comfort Care and Safety.

- $\quad$ Food Choices, Nutrition \& Diet

Figure1, displays theidentified Patient Centric Hospitality Programmes, covering the different domains of the hospitality services offered to patients in these hospitals. 


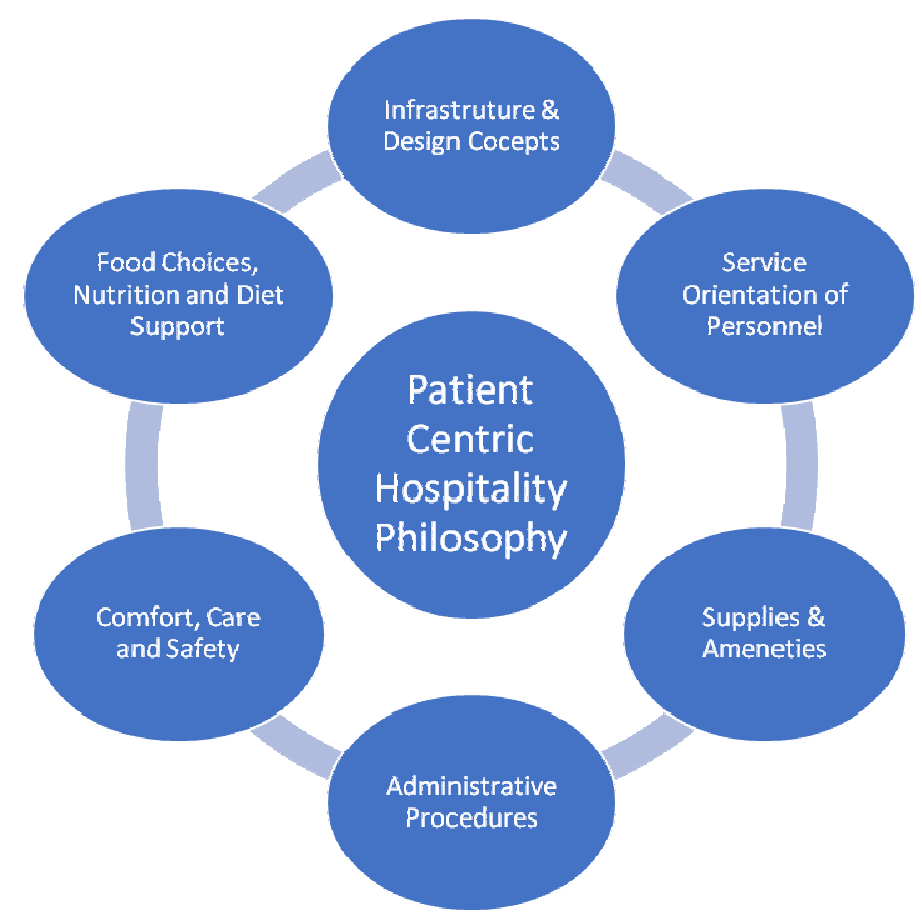

Figure 1: PCHPr Contributing to PCHP.

In the hospitalscovered for the study, all the attention of the guest service departments was focused on the betterment towards the excellence in each of the hospitality Programmes- PCHPr, covering a domain or the few hospitality elements of the overall hospitality environment offered as a goal and objective of Hospitality Policy under the overall PCHP.

Table 1.1, Describes the domains and Elements, broadly covered in each of the hospitality programme.

Table 1: Hospitality Elements Covered in Each Hospitality Programmes

\begin{tabular}{|c|l|l|}
\hline $\begin{array}{c}\text { S. } \\
\text { No }\end{array}$ & $\begin{array}{c}\text { Hospitality } \\
\text { Programme }\end{array}$ & \multicolumn{1}{c|}{ Hospitality Aspects Covered } \\
\hline 1 & $\begin{array}{l}\text { Infrastructure } \\
\text { Design } \\
\text { Concepts }\end{array}$ & $\begin{array}{l}\text { Hotel like impressive building design, Pleasantness of Surroundings, Signages and } \\
\text { Locators, special décor, comfortable room size etc. }\end{array}$ \\
\hline 2 & $\begin{array}{l}\text { Service } \\
\text { Orientation of } \\
\text { Personnel }\end{array}$ & $\begin{array}{l}\text { Polite and courteous uniformed staff, anticipating individual needs, teamwork } \\
\text { among all staff, quick service recovery, responsiveness and caring attitude of staff, } \\
\text { etc. }\end{array}$ \\
\hline 3 & $\begin{array}{l}\text { Supplies and } \\
\text { Amenities }\end{array}$ & $\begin{array}{l}\text { Comfortable room furniture, service directory, safety locker, appropriate sleeping } \\
\text { arrangement for attendant, 24/7 in room service etc. }\end{array}$ \\
\hline 4 & $\begin{array}{l}\text { Administrative } \\
\text { Procedures }\end{array}$ & $\begin{array}{l}\text { Smooth and efficient billing and registration process, readiness of room at arrival, } \\
\text { error free billing and multiple mode of payments etc. }\end{array}$ \\
\hline 5 & $\begin{array}{l}\text { Comfort Care } \\
\text { and Safety. }\end{array}$ & $\begin{array}{l}\text { Accessibility and convenience for disable, independent temp control in rooms, } \\
\text { non-slippery floors, quite surroundings, enough lighting, housekeeping and } \\
\text { cleanliness, transportation to different areas of hospital, patient counselling etc. }\end{array}$ \\
\hline 6 & $\begin{array}{l}\text { Food Choices, } \\
\text { Nutrition \& } \\
\text { Diet }\end{array}$ & $\begin{array}{l}\text { Food choices and variety, different dinning options, dietary counselling, taste \& } \\
\text { flavour and freshness of food, temp.of food served etc. }\end{array}$ \\
\hline
\end{tabular}

In all the hospitals studied, visible Public HospitalityProgrammewas found to be present and was taken care by guest service department, mostly situated in the main lobby of the hospital. They depute on site guest service associates to handle the multiple guest errands and concierge duties. This feature is quite similar to what concierge desk, present in all 
start hotels, does. The concierge desk has been added to hospitals to ease the arrival and the departure and also the staying experience of patients and their families as well as visitors. Airport pickup and drop, valet services, travel desk, shuttle from parking to main building, flower shop, bookshop and other helpdesk are the main examples of public hospitality display.

Personal Hospitality Programme included patient feedback system, rounds of hospitality managers, Nutrition and dietetic counselling, patient history card, patient advocacy and staff feedback are few examples of Personal Hospitality programme.

Taking rounds for collecting the personal feedback of patients and their families for their comforts and needs. This has always been a major display of their concerns towards the personal hospitality. According to Studer (2003), through staff feedback collected in a constructive and consistent way, managers can discover the first hand information on efficiency of system and effectiveness of decisions, along with bringing more loyalty from staff. This was clearly established that staff satisfaction level has a direct and positive linear relationship with patient satisfaction. (Studer, 2003).

The patient counselling programmes were also found to be in place in the hospitals. They are trained in clinical counselling to provide empathetic \&caring support to patients and their families, which may be startled, worried, or distraught.

Patent Centric Hospitality Programme, focusing on the Therapeutic Hospitality included the following -

- $\quad$ Spiritual healing and support,

- Yoga and Naturopathy,

- $\quad$ Alternate medicine,

- Holistic Healing,

- Clinical Counselling

- Diet Counselling

Finally, all the information gathered from hospitals indicate that the hospitals in the study has a fully functional and well-crafted PCHP in place. It is based on the Patient Centric Hospitality being visibly present and felt in physical environment, staff behaviours, administrative procedures, Infrastructure and design, supplies and amenities, availability of food choices, patient care and comfort protocols, Safety policy and procedures and \& Quality policy of the hospital. 


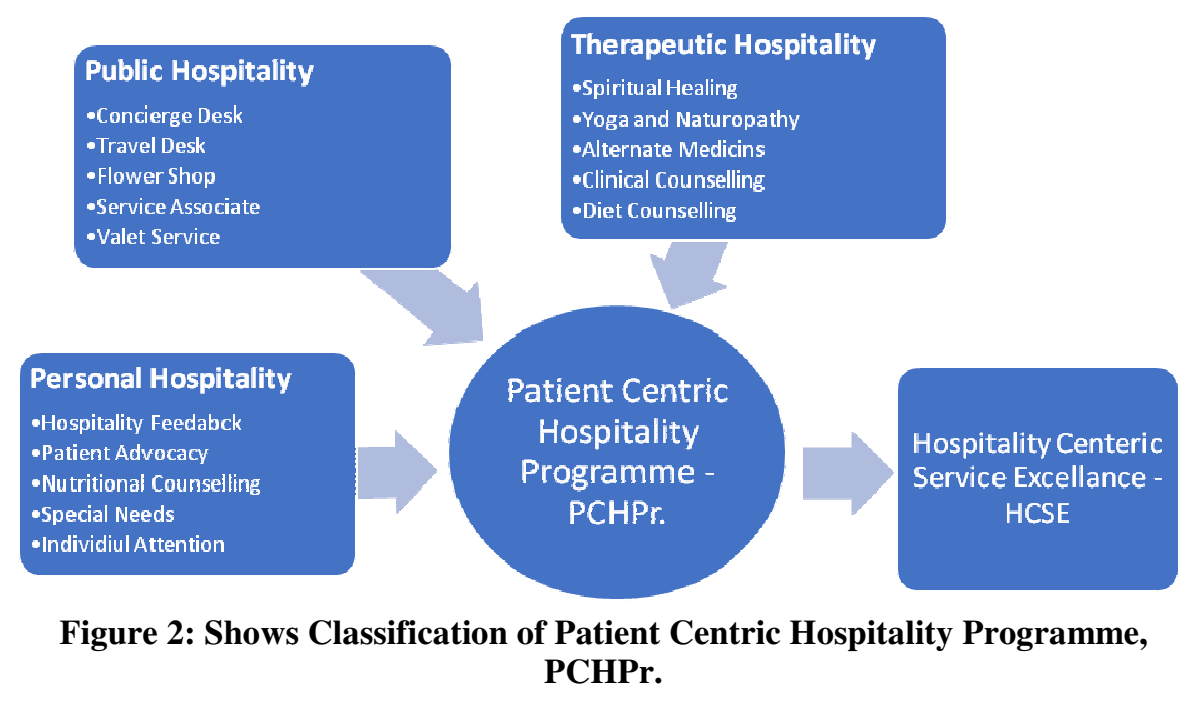

Figure 2,shows that together all the variety of Hospitality Programmes, as part of larger Hospitality Policy and Hospitality Philosophy as organizational support, can lead to Enhanced Service Excellence, often termed as a higher order term known as Hospitality Centric Service Excellence - HCSE.

\section{CONCLUSIONS AND IMPLICATIONS}

It can be concluded that an impartially diverse PCHP, which is supported with equally diverse and significantly effective PCHPr is in place in the hospitals selected for the study. This PCHP is also supported by management and observed as a scheme to augment the service excellence towards better patient satisfaction.

These hospitals intended to bring hospitality for patients and their families, which is at par with service experience received by guests in a star hotel. All the hotels have a fully functional directorate of hospitality services, a quality assurance cell for patient care. Some hospitals have also brought external hospitality consultant to meet regularly with Hospitality excellence committee. Additionally, many diverse and yet formal PCHPrhad been structured and created to facilitate the accomplishment of PCHP.The study also established that an effectively implemented PCHP can create path towards bringing the enhanced service excellence.

As the PCHP is elaborated as a distinct philosophy which is organization wide practice and is supported by the PCHPr which are smaller objectives within the bigger goal. This can be elucidated as the path to enhance the service excellence towards the better patient satisfaction. A PCHP is practiced in the form of hospitality centric goals, special support teams, and setting specific service excellence targets for each PCHPr.

Finally, this study found "HCSE - Hospitality Centric Service Excellence", as a advanced degree ofservice brilliance consequence which is more likely to be attained through a PCHP.

\section{Limitations and Future Research}

Presently, Delhi NCR is poised at becoming the preferred Indian destination, in south east Asia, for healthcare tourism. FICCI and ASOCCHAM, both have predicted the Indian Capitals region to be most popular healthcare destination having best of the medical talent and world-class hospitalfacilities too offer at a very competitive price. 
This success as a preferred medical tourism destination is well answered by looking at the world-class hospitality setup, which is offered to all International patients.

Researcher had the limitation of not being able to collect the real-time feedback from medical tourists to understand their perception towards the hospitality policy of the hospitals.

Future research can be performed in other not so established health tourism destination of the country.

\section{REFERENCES}

1. (PDF) Hospitality in hospitals: The importance of caring about the patient. (n.d.). Retrieved August 14, 2020, from https://www.researchgate.net/publication/305648317_Hospitality_in_hospitals_The_importance_of_caring_about_the_patient

2. Andrade, C. C., \& Devlin, A. S. (2015). Stress reduction in the hospital room: Applying Ulrich's theory of supportive design. Journal of Environmental Psychology, 41, 125-134. https://doi.org/10.1016/j.jenvp.2014.12.001

3. Bitner, M. J. (1990). Evaluating Service Encounters: The Effects of Physical Surroundings and Employee Responses. Journal of Marketing, 54(2), 69. https://doi.org/10.2307/1251871

4. Bitner, M. J. (1992). Servicescapes: The Impact of Physical Surroundings on Customers and Employees. Journal of Marketing, 56(2), 57-71. https://doi.org/10.1177/002224299205600205

5. Brotherton, B. (1999). Towards a definitive view of the nature of hospitality and hospitality management. International Journal of Contemporary Hospitality Management, 11(4), 165-173. https://doi.org/10.1108/09596119910263568

6. CIHF Hospitality, Health, and Design Symposium featured in article - Cornell Institute for Healthy Futures. (n.d.). Retrieved August 14, 2020, from https://ihf.cornell.edu/news/cihf-in-the-news/cihf-hospitality-health-and-design-symposium-featured-in-the-cornell-chronicleaugust-22-2016/

7. Cohen, S. (2004). Cohen (2004) - Social Relationships and Health. American Psychologist, November. https://doi.org/10.1177/0194599813477823

8. creswell $2003 \quad$ - $\quad$ Google Search. $\quad$ (n.d.). $\quad$ Retrieved August https://www.google.com/search?authuser=1\&source=hp\&ei=nMY2X87OMI3jgwfhgJiYDA\&q=creswell+2003\&gs_ssp=eJzj4tVP1zc0zDC2y MmpijcwYPTiTS5KLS5PzclRMDIwMAYAiFgIwQ\&oq=Creswell\%2C+2003\&gs_lcp=CgZwc3ktYWIQARgAMgUILhCTAjICCAAyAggAOgUI ABCXAzoOCC4QsQMQgwEQxwEQowI6CwguELEDEMcBEKMCOgIILjoICAAQsQMQgwFKBQgEEgExSgUIBxIBMVCbOVijSWCna2gCcA B4AIABmQSIAdUHkgEFNCOxLjGYAQCgAQGgAQKqAQdnd3Mtd2l6sAEA\&sclient=psy-ab

9. Davis, K., Schoenbaum, S. C., \& Audet, A. M. (2005). A 2020 vision of patient-centered primary care. In Journal of General Internal Medicine (Vol. 20, Issue 10, pp. 953-957). Springer. https://doi.org/10.1111/j.1525-1497.2005.0178.x

10. Evans, G. W., \& Mccoy, J. M. (1998). ENVIRONMENTAL PSYCHOLOGY Journalof WHEN BUILDINGS DON'T WORK: THE ROLE OF ARCHITECTURE IN HUMAN HEALTH. In Journal of Environmental Psychology (Vol. 18).

11. Gesler, W., Bell, M., Curtis, S., Hubbard, P., \& Francis, S. (2004). Therapy by design: evaluating the UK hospital building program. Health \& Place, 10, 117-128. https://doi.org/10.1016/S1353-8292(03)00052-2

12. Handbook of Hospitality Marketing Management - Google Books. (n.d.). Retrieved August 14, 2020, from https://books.google.co.in/books/about/Handbook_of_Hospitality_Marketing_Manage.html?id=_36OLR1ICxkC\&redir_esc=y

13. Haque, A., Sarwar, A., Yasmin, F., \& Anwar, A. (2012). The impact of customer perceived service quality on customer satisfaction for private health centre in Malaysia: a structural equation modeling approach. Information Management and Business Review, 4(5), 257.

14. Healing Places - 9780742519565. (n.d.). Retrieved August 14, 2020, from https://rowman.com/isbn/0742519562

15. Hussain, A., Sial, M. S., Usman, S. M., Hwang, J., Jiang, Y., \& Shafiq, A. (2019). What factors affect patient satisfaction in public sector hospitals: Evidence from an emerging economy. International Journal of Environmental Research and Public Health, 16(6). https://doi.org/10.3390/ijerph16060994 
16. Hutton, J. D., \& Richardson, L. D. (1995). Healthscapes: The role of the facility and physical environment on consumer attitudes, satisfaction, quality assessments, and behaviors. Health Care Management Review, 20(2), 48-61. https://doi.org/10.1097/00004010-199502020-00008

17. Kelly, R., Losekoot, E., \& Wright-StClair, V. A. (2016). Hospitality in hospitals: The importance of caring about the patient. Hospitality and Society, 6(2), 113-129. https://doi.org/10.1386/hosp.6.2.113_1

18. Kitapci, O., Akdogan, C., \& Dortyol, I. T. (2014). The Impact of Service Quality Dimensions on Patient Satisfaction, Repurchase Intentions and Word-of-Mouth Communication in the Public Healthcare Industry. Procedia - Social and Behavioral Sciences, $148,161-169$. https://doi.org/10.1016/j.sbspro.2014.07.030

19. Lashley, C. (2015). Hospitality and hospitableness. Research in Hospitality Management, 5(1), 1-7. https://doi.org/10.1080/22243534.2015.11828322

20. Lynch, P., Molz, J. G., Mcintosh, A., Lugosi, P., \& Lashley, C. (2011). Theorizing hospitality. In Hospitality and Society (Vol. 1, Issue 1, pp. 3-24). Intellect Ltd. https://doi.org/10.1386/hosp.1.1.3_2

21. O'Gorman, K. D. (2007). The hospitality phenomenon: philosophical enlightenment? International Journal of Culture, Tourism and Hospitality Research, 1(3), 189-202. https://doi.org/10.1108/17506180710817729

22. Oh, H., Pizam, A., \& Bojanic, D. (2008). Handbook of Hospitality Marketing Management PLEASE SCROLL DOWN FOR DOCUMENT. https://doi.org/10.4324/9780080569437.ch3

23. Oneview. (2015). The Eight Principles of Patient-Centered Care · Oneview. Https://Www.Oneviewhealthcare.Com/the-Eight-Principles-ofPatient-Centered-Care/. https://www.oneviewhealthcare.com/the-eight-principles-of-patient-centered-care/

24. Padma, P., Lokachari, P. S., \& Chandrasekharan, R. (2014). Strategic action grids: A study in Indian hospitals. International Journal of Health Care Quality Assurance, 27(5), 360-372. https://doi.org/10.1108/IJHCQA-11-2012-0108

25. Panchapakesan, P., Sai, L. P., \& Rajendran, C. (2015). Customer satisfaction in Indian hospitals: Moderators and mediators. Quality Management Journal, 22(1), 10-29. https://doi.org/10.1080/10686967.2015.11918416

26. Picker Institute's Eight Principles of Patient-Centered Care| National Center for Interprofessional Practice and Education. (n.d.). Retrieved August 14, 2020, from https://nexusipe.org/informing/resource-center/picker-institute's-eight-principles-patient-centered-care

27. Pizam, A. (2007). The “ity” Factor. Rosen Faculty Scholarship and Creative Works, 26(3). https://stars.library.ucf.edu/rosenscholar/297

28. Rathert, C., Wyrwich, M. D., \& Boren, S. A. (2013). Patient-centered care and outcomes: a systematic review of the literature. Medical Care Research and Review : MCRR, 70(4), 351-379. https://doi.org/10.1177/1077558712465774

29. Reynolds, D., \& Leeman, D. (2007). Does Combining Health Care Hospitality Services Increase Efficiency? Journal of Hospitality and Tourism Research. https://doi.org/10.1177/1096348006297289

30. Severt, D., Aiello, T., Elswick, S., \& Cyr, C. (2008a). Hospitality in hospitals? International Journal of Contemporary Hospitality Management, 20(6), 664-678. https://doi.org/10.1108/09596110810892227

31. Severt, D., Aiello, T., Elswick, S., \& Cyr, C. (2008b). Hospitality in hospitals? International Journal of Contemporary Hospitality Management, 20(6), 664-678. https://doi.org/10.1108/09596110810892227

32. Silvis, J. (2013). HCD Mag. https://www.healthcaredesignmagazine.com/architecture/saving-water-saving-money/

33. Sloane, D. C. (2001). Healthcare Architecture in an Era of Radical Transformation (review). Bulletin of the History of Medicine, 75(4), 832833. https://doi.org/10.1353/bhm.2001.0195

34. Suess, C., \& Mody, M. A. (2018). Hotel-like hospital rooms' impact on patient well-being and willingness to pay: An examination using the theory of supportive design. International Journal of Contemporary Hospitality Management, 30(10), 3006-3025. https://doi.org/10.1108/IJCHM-04-2017-0231

35. Swain, S., \& Kar, N. C. (2018). Hospital service quality as antecedent of patient satisfaction - a conceptual framework. International Journal of Pharmaceutical and Healthcare Marketing, 12(3), 251-269. https://doi.org/10.1108/IJPHM-06-2016-0028 
36. Verma, R., Shepley, M., \& Hollis, B. (2016). Proceedings: Cornell Symposium: Hospitality, Health \& Design HHDS2016 In Search of a Healthy Future. CIHF Collection. https://scholarship.sha.cornell.edu/cihfcoll/7

37. Wu, Z., Robson, S., \& Hollis, B. (2013). The application of hospitality elements in hospitals. Journal of Healthcare Management. https://doi.org/10.1097/00115514-201301000-00009 